Published in final edited form as: Support Care Cancer. 2016 Jan;24(1):195-203. doi: 10.1007/s00520-015-2746-1.

\title{
Cancer's positive flip side: Posttraumatic growth after childhood cancer
}

\author{
Micòl E. Gianinazzi ${ }^{1}$, Corina S. Rueegg ${ }^{1}$, Janine Vetsch ${ }^{1}$, Sonja Lüer ${ }^{2}$, Claudia E. Kuehni ${ }^{3}$ and Gisela \\ Michel $^{1,3}$; for the Swiss Pediatric Oncology Group (SPOG) \\ ${ }^{1}$ Department of Health Sciences and Health Policy, University of Lucerne, Lucerne, Switzerland \\ ${ }^{2}$ Department of Pediatrics, Division of Pediatric Hematology/Oncology, Inselspital, Bern, University of Bern, Switzerland \\ ${ }^{3}$ Swiss Childhood Cancer Registry, Institute of Social and Preventive Medicine, University of Bern, Bern, Switzerland
}

Swiss Pediatric Oncology Group (SPOG) Scientific Committee: Prof. Dr. med. R. Ammann, Bern; Dr. med. R. Angst, Aarau; Prof. Dr. med. M. Ansari, Geneva; PD Dr. med. M. Beck Popovic, Lausanne; Dr. med. E. Bergstraesser, Zurich; Dr. med. P. Brazzola, Bellinzona; Dr. med. J. Greiner, St. Gallen; Prof. Dr. med. M. Grotzer, Zurich; Dr. med. H. Hengartner, St. Gallen; Prof. Dr. med. T. Kuehne, Basel; Prof. Dr. med. C. Kuehni, Bern; Prof. Dr. med. K. Leibundgut, Bern; Prof. Dr. med. F. Niggli, Zurich; PD Dr. med. J. Rischewski, Lucerne; Prof. Dr. med. N. von der Weid, Basel

\section{Corresponding author:}

Prof. Dr. phil. Gisela Michel

Department of Health Sciences and Health Policy, University of Lucerne Frohburgstrasse 3, 6002 Lucerne, Switzerland Email: gisela.michel@unilu.ch

Telephone: +41412295955

Fax: +41412295635

Conflict of interest statement: No conflict of interest stated for any of the authors.

\begin{abstract}
Background: Surviving childhood cancer may result in positive psychological changes called posttraumatic growth (PTG). Knowing about the possibility of positive changes may facilitate survivors' reintegration in daily life. We aimed to: 1) describe PTG in Swiss childhood cancer survivors including the most and the least common PTG phenomena on the subscale and item level; and 2) determine factors associated with PTG.

Method: Within the Swiss Childhood Cancer Survivor Study (SCCSS) we sent two questionnaires to childhood cancer survivors registered in the Swiss Childhood Cancer Registry (SCCR). Eligible survivors were diagnosed after 1990 at age $\leq 16$ years, survived $\geq 5$ years and were aged $\geq 18$ years at the time the second questionnaire was sent. We included the Post-Traumatic-Growth-Inventory (PTGI) to assess 5 areas of PTG. We investigated the association of PTG with socio-demographic characteristics, selfreported late-effects, psychological distress, which were assessed in the SCCSS and clinical variables extracted from the SCCR. We used descriptive statistics to describe PTG and linear regressions to investigate factors associated with PTG.

Results: We assessed PTG in 309 childhood cancer survivors. Most individuals reported to have experienced some PTG. The most endorsed change occurred in "relation with others", the least in "spiritual change". PTG was significantly higher in survivors with older age at diagnosis $(\mathrm{p}=0.001)$ and those with longer duration of treatment $(p=0.042)$, while it was lower in male survivors $(p=0.003)$. Conclusions: Supporting experiences of PTG during follow-up may help survivors successfully return to daily life.
\end{abstract}

Key words: childhood cancer survivors; questionnaire survey; cohort study; posttraumatic growth.

\section{Citation:}

Gianinazzi, Micòl E; Rueegg, Corina S; Vetsch, Janine; Lüer, Sonja; Kuehni, Claudia E; Michel, Gisela (2016). Cancer's positive flip side: posttraumatic growth after childhood cancer.Supportive care in cancer, 24(1), p. 195-203. Springer 10.1007/s00520-015-2746-1 
Published in final edited form as: Support Care Cancer. 2016 Jan;24(1):195-203. doi: 10.1007/s00520-015-2746-1.

\section{Introduction}

Surviving cancer may result in positive psychological changes [1-4]. It is widely recognized that life-threatening and traumatic experiences have a radical impact on a person's existence redefining priorities, objectives and perceptions [5]. They can lead to posttraumatic stress and other emotional difficulties such as depression, somatization and anxiety [6-9], but they can also bring positive experiences. Tedeschi and Calhoun termed this phenomenon Posttraumatic Growth (PTG) and defined it as the subjective experience of positive psychological change reported by an individual as a result of the struggle with highly challenging life circumstances [10]. According to the authors, the greater the life threat, the bigger the potential for growth [11].

The number of scientific papers in the field of PTG has increased in the past few years and addressed several groups of traumatized individuals such as war veterans, survivors of environmental disasters, but also patients with a life threatening disease such as cancer patients. These studies showed that the cancer experience can result in PTG [1, 3, 5, 12-17]. Research conducted in adult cancer patients demonstrated that $80 \%$ of patients experienced positive psychological changes at different points during the cancer continuum [3, 5, 15, 16]. Similar results were published from studies carried out among childhood cancer and adolescent cancer survivors [1, 2, 4, 14, 17-21].

There are two main reasons why investigating PTG is important. First, knowing and acknowledging that after cancer even a positive change such as PTG can occur could change the view on cancer survivorship and facilitate survivors' and families' reintegration in daily life. Second, results of such research could help develop interventions to prevent the occurrence of negative late effects while promoting psychological health.

In childhood cancer survivors various sociodemographic and clinical variables were found to be differently associated with PTG. Among the socio-demographic factors being female and of non-Caucasian ethnicity were associated with higher PTG [1], while income, education and marital status were associated only to certain subscales of PTG [1]. While ethnicity may play a less important role in Switzerland, the other variables may also be relevant to Swiss childhood cancer survivors. Regarding clinical variables existing literature showed that having had more intensive treatments, being older at the time of diagnosis and shorter after diagnosis were associated with higher PTG [1, 14, 22]. All the above mentioned clinical variables may also be of interest for Swiss childhood cancer survivors when assessing PTG.

In the present study we aimed to 1) describe PTG in Swiss childhood cancer survivors including the most and the least common PTG phenomena on the subscale and item level; and 2) determine factors associated with PTG.

\section{Patients and methods}

Sample and Procedure

The Swiss Childhood Cancer Registry (SCCR) is a population-based registry including all Swiss residents diagnosed with leukemia, lymphoma, CNS tumor, malignant solid tumor or Langerhans cell histiocytosis before age 21 years [23, 24]. The Swiss Childhood Cancer Survivor Study (SCCSS) is a nationwide, long-term follow-up study of all patients registered in the SCCR who were diagnosed between 1976-2005 and survived for at least 5 years [25]. Between 2007 and 2009 all survivors received an initial information letter about the SCCSS from their former treating institution asking them to report if they did not wish to participate, if their address had changed, or if they required the questionnaire in another language. Two weeks later, all survivors received a paper-based questionnaire with a prepaid return envelope. Non-responders received another questionnaire after 2 months and if they still did not answer, were then contacted by phone. Questionnaires were provided in the three national languages German, French and Italian.

After approximately 3 years all participants who had completed the first questionnaire, were aged 18 years and older, and diagnosed with cancer at age $\leq 16$ years between 1990-2005, received a second questionnaire. Non-responders to this questionnaire got a reminder letter with a questionnaire and prepaid return envelope two months later. Because of few Italian speaking participants, the second questionnaire was provided only in German and French (two Italian 
Published in final edited form as: Support Care Cancer. 2016 Jan;24(1):195-203. doi: 10.1007/s00520-015-2746-1.

speaking survivors received the questionnaire in German, their second language).

Ethics approval was provided through the general cancer registry permission of the SCCR (The Swiss Federal Commission of Experts for Professional Secrecy in Medical Research) and a non obstat statement was obtained from the ethics committee of the canton of Bern.

The first questionnaire was based on those used in the US, and UK childhood cancer survivor studies [26, 27]. It contained the following main domains: psychological distress, quality of life, somatic health, current medication, health service utilization, fertility, health behavior and socio-economic information. The main focus of the second questionnaire was follow-up care and psychological outcomes (including PTG).

\section{Outcome variable: Posttraumatic Growth}

Posttraumatic Growth was assessed using the German and French versions of the Posttraumatic Growth Inventory (PTGI) [10]. The PTGI is a 21-item scale which comprises 5 subscales: Relating to Others (7 items): knowing that one can count on people in times of trouble; New Possibilities (5 items): having established a new path of life; Personal Strength (4 items): feeling of self-reliance; Spiritual Change (2 items): better understanding of spiritual matters; and Appreciation for life (3 items): being able to see what priorities are. Responders were asked to rate how much the disease has influenced the areas above on a 6-point Likert scale ranging from 0 "not at all" to 5 "extremely." Items are summed to obtain five subscale scores. A total PTG score can also be generated as the sum of all item scores. Higher scores suggest higher levels of PTG.As already shown by Tedeschi and Calhoun[10] Cronbach's alpha for our sample was also good to excellent: Relating to others $\alpha=0.72$, New possibilities $\alpha=0.87$, Personal strength $\alpha=0.81$, Spiritual change $\alpha=0.91$ and Appreciation of life $\alpha=0.91$. Confirmatory Factor Analysis testing the proposed 5-factor model [10, 1] derived a satisfactory Root Mean Square Error Approximation (RMSA) $\leq 0.08$ [28].

\section{Explanatory variables}

We extracted baseline demographic data and prospectively collected medical information on diagnosis and treatment from the Swiss Childhood Cancer Registry: age, gender, cancer diagnosis, age at diagnosis, cancer treatment, treatment duration, time since diagnosis and relapse. We used the following variables as continuous: age at study, time since diagnosis and treatment duration. We classified diagnosis according to the International Classification of Childhood Cancer - 3rd Edition [29]. For the regression analyses diagnoses were grouped into four categories: leukemia, lymphoma, tumors of the central nervous system (CNS), and other tumors. Treatment was coded hierarchically depending on its intensity: surgery only, chemotherapy (with or without surgery), radiotherapy (with surgery or chemotherapy), and bone marrow transplantation (BMT). Age at diagnosis was divided into three age categories: $\leq 5$ years, $5-10$ years and $\geq 10$ years.

Within the SCCSS questionnaires, we assessed migration background, survivors' education, self-reported late-effects, psychological distress and being in a relationship (partnership or marriage) (Supplemental Figure 1). We did not include race because not available and income because it contained too many missing values. Participants were classified as having a migrant background if they were not Swiss citizens since birth, not born in Switzerland, or had at least one parent who was not a Swiss citizen. Survivors' education was divided into four categories: primary (compulsory schooling only); secondary (including vocational training, teacher school, technical and commercial schools etc.); tertiary (including university and university of applied sciences); and those with unknown or still in education [30, 31]. To assess self-reported late effects we asked survivors we if they experienced any physical or psychological problems as a result of the cancer or treatment received (yes/no).

Psychological distress was assessed using the Brief Symptom Inventory-18 (BSI-18) both with the baseline and follow-up questionnaire [32]. The inventory yields three scales (somatization, depression and anxiety) and a Global Severity Index (GSI). Responders were asked to report 
Published in final edited form as: Support Care Cancer. 2016 Jan;24(1):195-203. doi: 10.1007/s00520-015-2746-1.

their degree of distress over the past 7 days using a five-point Likert scale ranging from zero ('not at all') to four ('extremely'). Raw scores were calculated by summing up all items on the respective scale. For participants who missed less than or equal to two items per scale, scores were calculated using the rounded average of the remaining items according to the manual's instructions. Survivors who had missed more than three items were not included in the analyses. T-scores of each scale were calculated according to the manual [33]. Higher scores indicate higher psychological distress. To identify distressed patients, we created an indicator for high psychological distress: individuals with a score of $\mathrm{T} \geq 57$ in at least two scales or on GSI where considered distressed.[6]

\section{Statistical Analyses}

First, descriptive statistics and frequencies were obtained for demographic and clinical variables to compare survey participants with nonparticipants. For this comparison we calculated chi-square statistics for categorical variables and independent t-tests for continuous variables.

Second, we used descriptive statistics to assess all PTG scales in Swiss childhood cancer survivors. We also computed the proportions of participants endorsing single items at a moderate or great level (score $\geq 3$ ) to be able to characterize the most common and most frequent forms of PTG [16].

Finally, we ran univariable linear regression to investigate the associations of PTGI's total score with demographic and clinical variables, and included all variables significant at the $\mathrm{p}<0.05$ level in the multivariable model. We performed all analyses using Stata 12.0 (StataCorp, College Station, TX).

\section{Results}

\section{Characteristics of the Study Population}

We contacted 720 eligible survivors. Of those, 321 (45\%) returned a questionnaire. We excluded 3 (0.5\%) survivors whose parents filled out the questionnaire, as well as $9(1 \%)$ who did not complete the PTGI (Supplemental Figure 2). Participants $\quad(n=309)$ compared to nonparticipants $(\mathrm{n}=408)$ were more often female ( $57 \%$ vs. $43 \%$; $p=0.001$ ), had higher education ( $19 \%$ vs. $13 \%$ with tertiary education, $\mathrm{p}=0.032$ ) and had been more often treated with radiotherapy and BMT and less often with surgery only ( $\mathrm{p}=0.029$; Table 1$)$. Participants reported more often to be suffering from lateeffects than non-participants (41\% vs. 33\%, $\mathrm{p}=0.026$ ). The two groups did not differ by migration background, relapse status, age at study, age at diagnosis and time since diagnosis, time since end of treatment and duration of treatment.

\section{Posttraumatic Growth in Swiss Childhood Cancer Survivors \\ PTGI scale-level analyses}

The average PTG total score in our sample of Swiss childhood cancer survivors was 51.9 (standard deviation $(S D)=22.0$ ). Total scores ranged from a low of 0 to a high of 102 (instrument's possible range 0 to 105).

Overall, Swiss childhood cancer survivors reported PTG especially in the scales "Relating to others" (mean=18.15; 95\% Confidence Interval [CI], 17.2-19.1) and in "New possibilities" (mean=12.2; CI, 11.5-12.9; Figure $1)$. The lowest score was found in "Spiritual change" (mean=2.3; CI, 2.0-2.6). Only few participants reported no positive change in one or several scales: 7 (2\%) in "Relating to others", 12 (4\%) in "Personal strength" 14 (5\%) each in "Appreciation of life" and "New possibilities". Finally, 3 survivors (1\%) reported no growth at all (score $=0$ in all scales).

PTGI item-level analysis

The five most endorsed items were "My priorities about what's important in life" and "Appreciation for the value of my life" (scale: Appreciation of life) endorsed by $74 \%$; "Knowing I can count on people" and "Having compassion for others" (scale: Relating to others) endorsed by $73 \%$ and $61 \%$, respectively; "Knowing I can handle difficulties" (scale: Personal strength) endorsed by 70\% (Figure 2). The following items were endorsed by less than $30 \%$ : "Better understanding of spiritual matters" (25\%), "I have a stronger religious faith" (17\%) (scale: Spiritual change”), "New opportunities are available” (29\%) (scale: New possibilities) (Figure 2).

\section{Characteristics of survivors experiencing PTG}

Younger age at diagnosis, longer time since diagnosis and higher psychological distress were 
Published in final edited form as: Support Care Cancer. 2016 Jan;24(1):195-203. doi: 10.1007/s00520-015-2746-1.

significantly associated with lower PTG (univariable linear regression, Table 2). Lower PTG, though not statistically significant, was reported by participants with male sex, having a migration background, a diagnosis of lymphoma or other solid tumor, and having had surgery only. Higher PTGI scores were reported by survivors with longer treatment duration, having suffered from a relapse or reporting to suffer from late effects. Older age (> 5 years), education, having a partner and bone marrow transplantation were also associated in a positive direction but not statistically significant.

The final model included sex, diagnosis, age at diagnosis, time since diagnosis, treatment duration, relapse, reporting late-effects and psychological distress. The direction of association for all factors remained similar in the multivariable model as in the univariable (Table 2 ). The effect of age at diagnosis was stronger, while the effect of treatment duration became weaker. Male sex became statistically significant in the multivariable model, while the remaining variables became weaker or not significant (Table 2).

\section{Discussion}

The majority of Swiss childhood cancer survivors reported to have developed some posttraumatic growth. At the subscale level the most changes were observed in "relating to others" and "new possibilities" while the lowest score was observed for "spiritual change". The two most endorsed items were from the scale "appreciation of life", while the least endorsed came from "spiritual change". Only 3 survivors (1\%) reported no PTG at all in any of the scales assessed. The experience of growth was stronger in survivors older at diagnosis and who had experienced longer duration of treatment, while it was reduced for male survivors.

Our results corroborate previous findings in research on PTG. Independently of the instrument and study design used, or the population and traumatic event studied, it is clear that a traumatic life event can lead to psychological growth [34, 35]. This also accounts for life-threatening diseases like cancer. PTG was found in adult cancer patients [3, 5, 13, $15,16,36]$, as well as in childhood cancer survivors $[1,2,4,14,18,21]$. In our study, the most salient area of positive change was in "Relating to others". This was similar to other studies of childhood cancer survivors [1-3, 36], where domains such as closeness and counting on people showed particularly positive change. Cancer diagnosis seems to remodel the interpersonal realm because of the new roles that are attributed to family members and friends [37]. On the other hand, spiritual change was not often reported by Swiss survivors. The role of religion in Switzerland as a mediator for difficulties has lost importance over the years and this tendency has been shown in other studies [38, 39]. At an item level the two most endorsed items ("My priorities about what is important in life" and "Appreciation for the value of my life" are both from the subscale appreciation of life. Exactly the same result was found in an article which also looked at item endorsement. [16]

When looking at factors promoting or preventing PTG in different studies, our findings are in line with previous studies reporting that males experienced less PTG than females [1, 10, 15]. Females seem to be able to cope better than men as it was already suggested in other research.[1, 18] In contrast to other research [1, 2] our study did not find a clear association with education or migration status. One possible reason could be that despite the differences regarding migration and education are present in Switzerland, these are not as marked as in the United States and do not seem to influence the experience of PTG. Similar to previous studies [14], we found that scores significantly increased with age (age at diagnosis: $\leq 5$ years: $\mathrm{PTG}=44.5$; $5-10$ years: $\mathrm{PTG}=54.4 ; \geq 10$ years: $\mathrm{PTG}=55.5$ ). Depending on age cognitive functions change and children start to differently process and reflect on their experiences.

Shorter time since diagnosis survivors seem to be more likely to experience PTG $[1,40]$. An explanation could be that with increasing time survivors return to a more normal life and the positive experiences associated with the cancer diagnosis diminish.

Cancer type and intensity of treatment were also found to be associated with PTG in other studies $[1,15]$. We also found higher PTG in survivors who had received more intense treatment regimens like radiotherapy and bone marrow 
Published in final edited form as: Support Care Cancer. 2016 Jan;24(1):195-203. doi: 10.1007/s00520-015-2746-1.

transplantation [1], and survivors who had a relapse or reported to have late-effects. In our study we also found that the level of suffering psychological distress is associated with lower levels of PTG. This is in contrast with other studies which shows that PTG is associated with higher posttraumatic stress [5], but clearly we have to bear in mind that psychological distress is not the same construct as posttraumatic stress, which is the specific result of a trauma.

Future research on PTG

In general, the construct PTG needs further evaluation, especially regarding its interplay with other domains of psychological health such as distress and posttraumatic stress in cancer patients. There is the necessity to understand whether PTG is a truly positive outcome of a person who has changed because of the adversity, or if it is the result of a coping strategy in which the patients' lives experience an illusionary gain. This conflicting outcome was proposed by Cordova and colleagues in 2001 [36] and was later theorized within the JanusFace model by Maercker and Zoellner [41]. A better understanding of the phenomenon could help promote PTG in the survivor population in a more targeted way. The present study can add important information to existing literature and will help to develop intervention studies to prevent the occurrence of negative late effects while promoting psychological health including PTG.

\section{Implications for practice}

Because research in this field is young and methodological questions still numerous, we have to be careful in drawing conclusions which are generalized to all childhood cancer survivors. However, there is growing evidence that childhood cancer may be followed by psychological growth and this can transform cancer survivorship from a merely pathogenic to a more salutogenic paradigm. Knowing and acknowledging this development could change features of the cancer's aftermath and facilitate survivors' reintegration in daily life. Posttraumatic growth is also one of the many facets of cancer survivorship and the only positive one studied up to now. The fact that literature is multiplying in this domain shows how important this perspective can be. Knowing that despite all the suffering and trauma there is still space for growth can instill hope in both, parents and survivors. Health care personnel should also bear in mind that positive change such as PTG can occur after a traumatic life and should also focus on a possible positive flip side of cancer - even during cancer treatment. As suggested by Maseraand colleagues (2013) in a recent publication it should be possible to induce resilience in childhood cancer survivors, by using for example famous sportsmen and sportswomen or other celebrities who have survived cancer [42]. Using PTG in a preventive way may not only benefit patients in terms of better quality of life and psychological health, but it may decrease, on the long term, the number of unneeded medical visits which occur as a result of higher distress.

\section{Strengths and Limitations}

The major strength of this study is the population-based sample of survivors with prospectively collected data on the cancerrelated factors from the Swiss Childhood Cancer Registry and data available from the baseline and follow-up questionnaires from the Swiss Childhood Cancer Survivor Study. A limitation might be self-selection because survivors of specific groups may have been more reluctant to complete the questionnaire, especially after having filled in the baseline questionnaire. The total response rate was $45 \%$. However, we found no indication that participants and nonparticipants differed in psychological distress at the baseline survey. Finally, PTG is a descriptive construct and the inventory used in this study is difficult to interpret. It is hard to quantify PTG because there is neither a norm population nor a cut-off helping quantifying PTG and it is unclear whether an inventory for general trauma covers the multifaceted cancer-experience.

\section{Conclusions}

Our study showed that Swiss childhood cancer survivors, particularly women and those older at diagnosis, experienced PTG; they especially reported that they can count on other people and that appreciate their life and know their priorities. Finding ways to promote PTG early on during and after treatment may help survivors translate their experiences with the life threatening disease into something meaningful for their future life. 
Published in final edited form as: Support Care Cancer. 2016 Jan;24(1):195-203. doi: 10.1007/s00520-015-2746-1.

Acknowledgements: We thank all survivors and their families for participating in our survey, the data managers of the Swiss Paediatric Oncology Group (Claudia Anderegg, Nadine Beusch, Rosa-Emma Garcia, Franziska Hochreutener, Friedgard Julmy, Nadine Lanz, Heike Markiewicz, Genevieve Perrenoud, Annette Reinberger, Renate Siegenthaler, Verena Stahel, and Eva Maria Tinner), and the team of the Swiss Childhood Cancer Registry (Vera Mitter, Elisabeth Kiraly, Marlen Spring, Christina Krenger, Priska Wolfli).

Financial support: This work was supported by the Swiss National Science Foundation (Ambizione grant PZ00P3_121682/1 and PZ00P3-141722 to GM), the Swiss Cancer League (grant KLS-01605-10-2004, KLS-221502-2008, KFS-02631-08-2010, KLS-02783-022011); Cancer League Bern; Cancer League Aarau; Swiss Bridge; and Stiftung zur Krebsbekämpfung. The work of the Swiss Childhood Cancer Registry is supported by the Swiss Paediatric Oncology Group (www.spog.ch), Schweizerische Konferenz der kantonalen Gesundheitsdirektorinnen und direktoren (www.gdk-cds.ch), Swiss Cancer Research (www.krebsforschung.ch), Kinderkrebshilfe Schweiz (www.kinderkrebshilfe.ch), Ernst-Göhner Stiftung, Stiftung Domarena and National Institute of Cancer Epidemiology and Registration (www.nicer.ch).

\section{References}

1. Zebrack BJ, Stuber ML, Meeske KA, Phipps S, Krull KR, Liu Q et al. Perceived positive impact of cancer among long-term survivors of childhood cancer: a report from the childhood cancer survivor study. Psychooncology. 2012;21(6):630-9.

2. Arpawong TE, Oland A, Milam JE, Ruccione $\mathrm{K}$, Meeske KA. Post-traumatic growth among an ethnically diverse sample of adolescent and young adult cancer survivors. PsychoOncology. 2013;22(10):2235-44. doi:10.1002/pon.3286.

3. Zwahlen D, Hagenbuch N, Carley MI, Jenewein J, Buchi S. Posttraumatic growth in cancer patients and partners--effects of role, gender and the dyad on couples' posttraumatic growth experience. Psychooncology. 2010;19(1):12-20. doi:10.1002/pon.1486.

4. Michel G, Taylor N, Absolom K, Eiser C. Benefit finding in survivors of childhood cancer and their parents: Further empirical support for the Benefit Finding Scale for Children. Child: Care, Health and Development. 2010;36:123-9.

5. Jim HS, Jacobsen PB. Posttraumatic stress and posttraumatic growth in cancer survivorship: a review. Cancer J. 2008;14(6):414-9.

6. Gianinazzi ME, Rueegg CS, Wengenroth L, Bergstraesser E, Rischewski J, Ammann RA et al. Adolescent survivors of childhood cancer: are they vulnerable for psychological distress? Psychooncology. 2013;11(10):20518. doi:DOI: 10.1002/pon.3249.

7. Michel G, Rebholz CE, von der Weid NX, Bergstraesser E, Kuehni CE. Psychological distress in adult survivors of childhood cancer: the Swiss Childhood Cancer Survivor study. Journal of Clinical Oncology. 2010;28(10):1740-8.

8. Zebrack BJ, Zevon MA, Turk N, Nagarajan R, Whitton J, Robison LL et al. Psychological distress in long-term survivors of solid tumors diagnosed in childhood: A report from the childhood cancer survivor study. Pediatric Blood \& Cancer. 2007;49(1):47-51. doi:10.1002/pbc.20914.

9. Zeltzer LK, Recklitis C, Buchbinder D, Zebrack B, Casillas J, Tsao JC et al. Psychological status in childhood cancer survivors: a report from the Childhood Cancer Survivor Study. Journal of Clinical Oncology. 2009;27(14):2396-404.

10. Tedeschi RG, Calhoun LG. The Posttraumatic Growth Inventory: measuring the positive legacy of trauma. J Trauma Stress. 1996;9(3):455-71.

11. Tedeschi RG, Calhoun LG, Cann A. Evaluating Resource Gain: Understanding and Misunderstanding Posttraumatic Growth. Applied Psychology. 2007;56(3):396-406.

12. Parry C, Chesler MA. Thematic evidence of psychosocial thriving in childhood cancer survivors. Qual Health Res. 2005;15(8):105573.

13. Cordova M, Giese-Davis J, Golant M, Kronenwetter C, Chang V, Spiegel D. Breast 
Published in final edited form as: Support Care Cancer. 2016 Jan;24(1):195-203. doi: 10.1007/s00520-015-2746-1.

Cancer as Trauma: Posttraumatic Stress and Posttraumatic Growth. Journal of Clinical Psychology in Medical Settings. 2007;14(4):308-19. doi:10.1007/s10880-0079083-6.

14. Barakat LP, Alderfer MA, Kazak AE. Posttraumatic growth in adolescent survivors of cancer and their mothers and fathers. J Pediatr Psychol. 2006;31(4):413-9.

15. Bellizzi KM, Blank TO. Predicting posttraumatic growth in breast cancer survivors. Health psychology : official journal of the Division of Health Psychology, American Psychological Association. 2006;25(1):47-56. doi:10.1037/02786133.25.1.47.

16. Widows MR, Jacobsen PB, Booth-Jones M, Fields KK. Predictors of Posttraumatic Growth Following Bone Marrow Transplantation for Cancer. Health Psychology. 2005;24(3):266-73. doi:10.1037/0278-6133.24.3.266.

17. Wasserman AL, Thompson EI, Wilimas JA, Fairclough DL. The psychological status of survivors of childhood/adolescent Hodgkin's disease. American journal of diseases of children (1960). 1987;141(6):626-31.

18. Kamibeppu K, Sato I, Honda M, Ozono S, Sakamoto N, Iwai T et al. Mental health among young adult survivors of childhood cancer and their siblings including posttraumatic growth. J Cancer Surviv. 2010. doi:10.1007/s11764-010-0124-z.

19. Turner-Sack AM, Menna R, Setchell SR. Posttraumatic growth, coping strategies, and psychological distress in adolescent survivors of cancer. J Pediatr Oncol Nurs. 2012;29(2):70-9.

20. Devine KA, Reed-Knight B, Loiselle KA, Fenton N, Blount RL. Posttraumatic growth in young adults who experienced serious childhood illness: a mixed-methods approach. J Clin Psychol Med Settings. 2010;17(4):3408. doi:10.1007/s10880-010-9210-7.

21. Duran B. Posttraumatic Growth as Experienced by Childhood Cancer Survivors and Their Families: A Narrative Synthesis of Qualitative and Quantitative Research. Journal of Pediatric Oncology Nursing. 2013;30(4):179-97.

22. Casillas JN, Zebrack BJ, Zeltzer LK. Healthrelated quality of life for Latino survivors of childhood cancer. J Psychosoc Oncol. 2006;24(3):125-45.

23. Michel G, von der Weid NX, Zwahlen M, Adam M, Rebholz CE, Kuehni CE et al. The Swiss Childhood Cancer Registry: rationale, organisation and results for the years 20012005. Swiss Med Wkly. 2007;137(3536):502-9. doi:2007/35/smw-11875.

24. Michel G, von der Weid NX, Zwahlen M, Redmond S, Strippoli M-PF, Kuehni CE. Incidence of childhood cancer in Switzerland: The Swiss childhood cancer registry. Pediatr Blood Cancer. 2008;50(1):46-51. doi:DOI 10.1002/pbc.21129.

25. Kuehni CE, Rueegg CS, Michel G, Rebholz CE, Strippoli MP, Niggli FK et al. Cohort profile: The Swiss Childhood Cancer Survivor Study. Int J Epidemiol. 2011. doi:10.1093/ije/dyr142.

26. Robison LL, Mertens AC, Boice JD, Breslow NE, Donaldson SS, Green DM et al. Study design and cohort characteristics of the Childhood Cancer Survivor Study: a multiinstitutional collaborative project. Med Pediatr Oncol. 2002;38(4):229-39.

27. Hawkins MM, Lancashire ER, Winter DL, Frobisher C, Reulen RC, Taylor AJ et al. The British Childhood Cancer Survivor Study: Objectives, methods, population structure, response rates and initial descriptive information. Pediatr Blood Cancer. 2008;50(5):1018-25.

28. Feinian Chen, Curran PJ, Bollen KA, Kirby J, Paxton P. An Empirical Evaluation of the Use of Fixed Cutoff Points in RMSEA Test Statistic in Structural Equation Models. Sociological Methods \& Research. 2008;36(4):462-94. doi:10.1177/0049124108314720.

29. Steliarova-Foucher E, Stiller C, Lacour B, Kaatsch P. International Classification of Childhood Cancer, third edition. Cancer. 2005;103(7):1457-67. doi:10.1002/cncr.20910.

30. Kuehni CE, Strippoli M-PF, Rueegg CS, Rebholz CE, Bergstraesser E, Grotzer $M$ et al. Educational achievement in Swiss childhood cancer survivors compared with the general population. Cancer. 2011;118(5):1439-49. doi:10.1002/cncr.26418. 
Published in final edited form as: Support Care Cancer. 2016 Jan;24(1):195-203. doi: 10.1007/s00520-015-2746-1.

31. German U. Abschlussbericht zur Volkszählung 2000. Neuchâtel: Bundesamt für Statistik; 2005.

32. Derogatis LR. BSI-18 Administration, Scoring, and Procedures Manual. Minneapolis, MN: National Computer Services; 2000.

33. Derogatis LR. Brief Symptom Inventory 18 (BSI 18). Minneapolis, MN: NCS Pearson; 2000.

34. Tedeschi RG. Posttraumatic growth in combat veterans. J Clin Psychol Med Settings. 2011;18(2):137-44.

35. Easton SD, Coohey C, Rhodes AM, Moorthy MV. Posttraumatic Growth Among Men With Histories of Child Sexual Abuse. Child Maltreat. 2013;4:4.

36. Cordova MJ, Cunningham LL, Carlson CR, Andrykowski MA. Posttraumatic growth following breast cancer: a controlled comparison study. Health psychology : official journal of the Division of Health Psychology, American Psychological Association. 2001;20(3):176-85.

37. Tanriverd D, Savas E, Can G. Posttraumatic growth and social support in Turkish patients with cancer. Asian Pac J Cancer Prev. 2012;13(9):4311-4.

38. Morris BA, Shakespeare-Finch J, Scott JL. Posttraumatic growth after cancer: the importance of health-related benefits and newfound compassion for others. Support Care Cancer. 2012;20(4):749-56.

39. Bovay C BR. Religionslandschaft in der Schweiz [Religion in Switzerland]. Abschlussbericht zur Volkszählung 2000. Neuchâtel: Bundesamt für Statistik; 2005.

40. Phipps S, Long A, Hudson M, Rai SN. Symptoms of post-traumatic stress in children with cancer and their parents: effects of informant and time from diagnosis. Pediatr Blood Cancer. 2005;45(7):952-9.

41. Zoellner T, Maercker A. Posttraumatic growth in clinical psychology - a critical review and introduction of a two component model. Clin Psychol Rev. 2006;26(5):626-53.

42. Masera G, Chesler MA, Zebrack B, D'Angio GJ. Cure Is Not Enough: One Slogan, Two Paradigms for Pediatric Oncology. Pediatr Blood Cancer. 2013;60:1069-70. 
Table 1: Characteristics of the study population, comparing survivor participants and non-participants of the follow up questionnaire

\begin{tabular}{|c|c|c|c|c|c|}
\hline & \multicolumn{2}{|c|}{$\begin{array}{c}\text { Participants } \\
(n=309)\end{array}$} & \multicolumn{2}{|c|}{$\begin{array}{c}\text { Non-participants } \\
(n=408)\end{array}$} & \multirow[b]{2}{*}{ p-value ${ }^{b}$} \\
\hline & $\mathbf{n}$ & $\%^{a}$ & $\mathbf{n}$ & $\%^{\mathrm{a}}$ & \\
\hline \multicolumn{6}{|l|}{ Sex } \\
\hline Male & 134 & 43 & 234 & 57 & 0.001 \\
\hline Female & 175 & 57 & 174 & 43 & \\
\hline \multicolumn{6}{|l|}{ Migration background } \\
\hline None (Swiss) & 284 & 92 & 368 & 90 & 0.429 \\
\hline Other countries & 25 & 8 & 40 & 10 & \\
\hline \multicolumn{6}{|l|}{ Education } \\
\hline Primary & 29 & 10 & 56 & 12 & 0.032 \\
\hline Secondary & 92 & 29 & 136 & 34 & \\
\hline Tertiary & 59 & 19 & 48 & 13 & \\
\hline Unknown or in education & 129 & 42 & 172 & 41 & \\
\hline \multicolumn{6}{|l|}{ Diagnosis (ICCC-3) } \\
\hline I Leukemia & 108 & 35 & 128 & 31 & 0.779 \\
\hline II Lymphoma & 59 & 19 & 83 & 20 & \\
\hline III CNS tumor & 37 & 11 & 64 & 17 & \\
\hline IV Neuroblastoma & 8 & 4 & 13 & 5 & \\
\hline V Retinoblastoma & 5 & 2 & 9 & 2 & \\
\hline VI Renal tumor & 21 & 6 & 21 & 5 & \\
\hline VII Hepatic tumor & 1 & 1 & 3 & 1 & \\
\hline VIII Bone tumor & 22 & 7 & 23 & 6 & \\
\hline IX Soft tissue sarcoma & 19 & 6 & 20 & 5 & \\
\hline X Germ cell tumor & 9 & 3 & 17 & 3 & \\
\hline XI \& XII Other tumor ${ }^{\mathrm{C}}$ & 8 & 2 & 6 & 1 & \\
\hline Langerhans Cell Histiocytosis & 12 & 4 & 21 & 4 & \\
\hline \multicolumn{6}{|l|}{ Treatment } \\
\hline Surgery only & 34 & 11 & 74 & 18 & 0.029 \\
\hline Chemotherapy & 145 & 47 & 192 & 47 & \\
\hline Radiotherapy & 99 & 32 & 108 & 27 & \\
\hline BMT & 31 & 10 & 31 & 8 & \\
\hline \multicolumn{6}{|l|}{ Relapse } \\
\hline No & 245 & 88 & 319 & 91 & 0.365 \\
\hline Yes & 33 & 12 & 34 & 9 & \\
\hline \multicolumn{6}{|l|}{ Reported late-effects } \\
\hline No & 185 & 59 & 249 & 67 & 0.026 \\
\hline \multirow[t]{2}{*}{ Yes } & 130 & 41 & 123 & 33 & \\
\hline & mean & (SD) & mean & (SD) & p-value ${ }^{d}$ \\
\hline Age at study (years) & 21.3 & 4.1 & 21.7 & 3.8 & 0.852 \\
\hline Age at diagnosis (years) & 8.9 & 4.7 & 8.9 & 4.5 & 0.512 \\
\hline Time since diagnosis (years) & 12.5 & 3.8 & 12.8 & 3.6 & 0.857 \\
\hline Time since treatment end (years) & 14.2 & 3.9 & 14.1 & 3.8 & 0.336 \\
\hline Therapy duration (years) & 1.4 & 1.8 & 1.3 & 1.7 & 0.370 \\
\hline
\end{tabular}

NOTE: Percentages are based upon available data for each variable. Abbreviations: BMT, Bone Marrow Transplantation, CNS, Central Nervous System; ICCC-3, International Classification of Childhood Cancer - Third

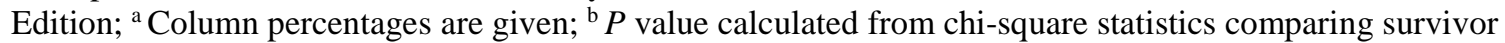
participants and survivor non-participants; ' Other malignant epithelial neoplasms, malignant melanomas and other or unspecified malignant neoplasms; ${ }^{\mathrm{d}} P$ value calculated on two-sample mean-comparison test (t-test). 
Table 2: Univariable and multivariable linear regression investigating the associations of socio-demographic and clinical factors with the PTGI total score

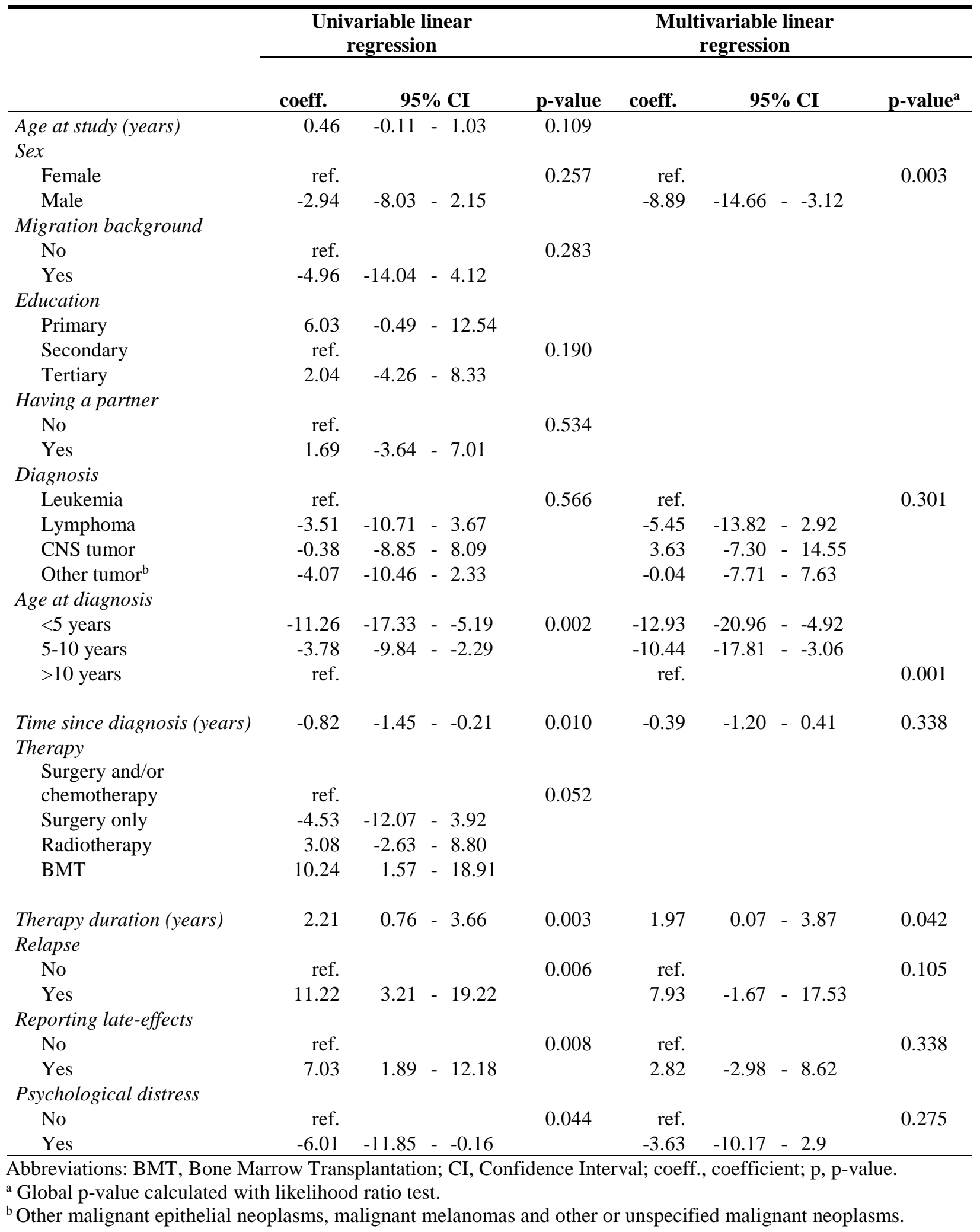


Figure 1: Radar chart displaying the distribution of data of the PTGI scale in Swiss Childhood Cancer Survivors (SCCSS)

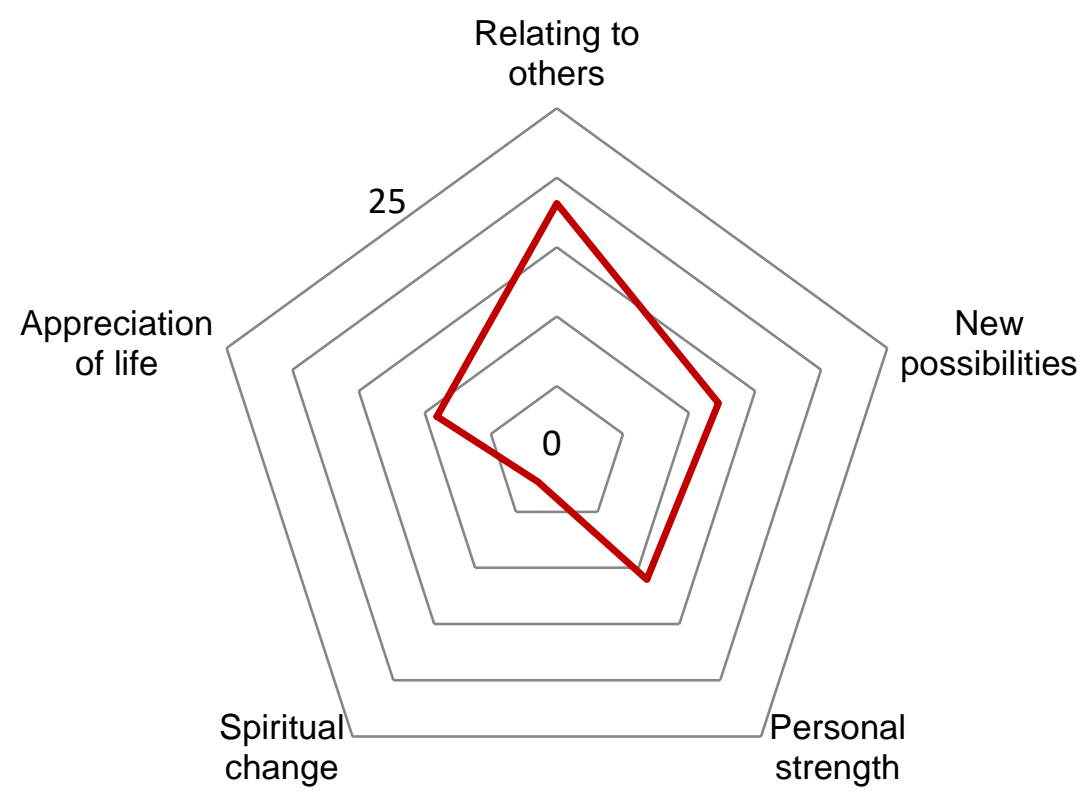

- SCCSS 
Figure 2 Proportion of participants endorsing the PTGI items at a moderate/great level

Posttraumatic Growth in Childhood Cancer Survivors

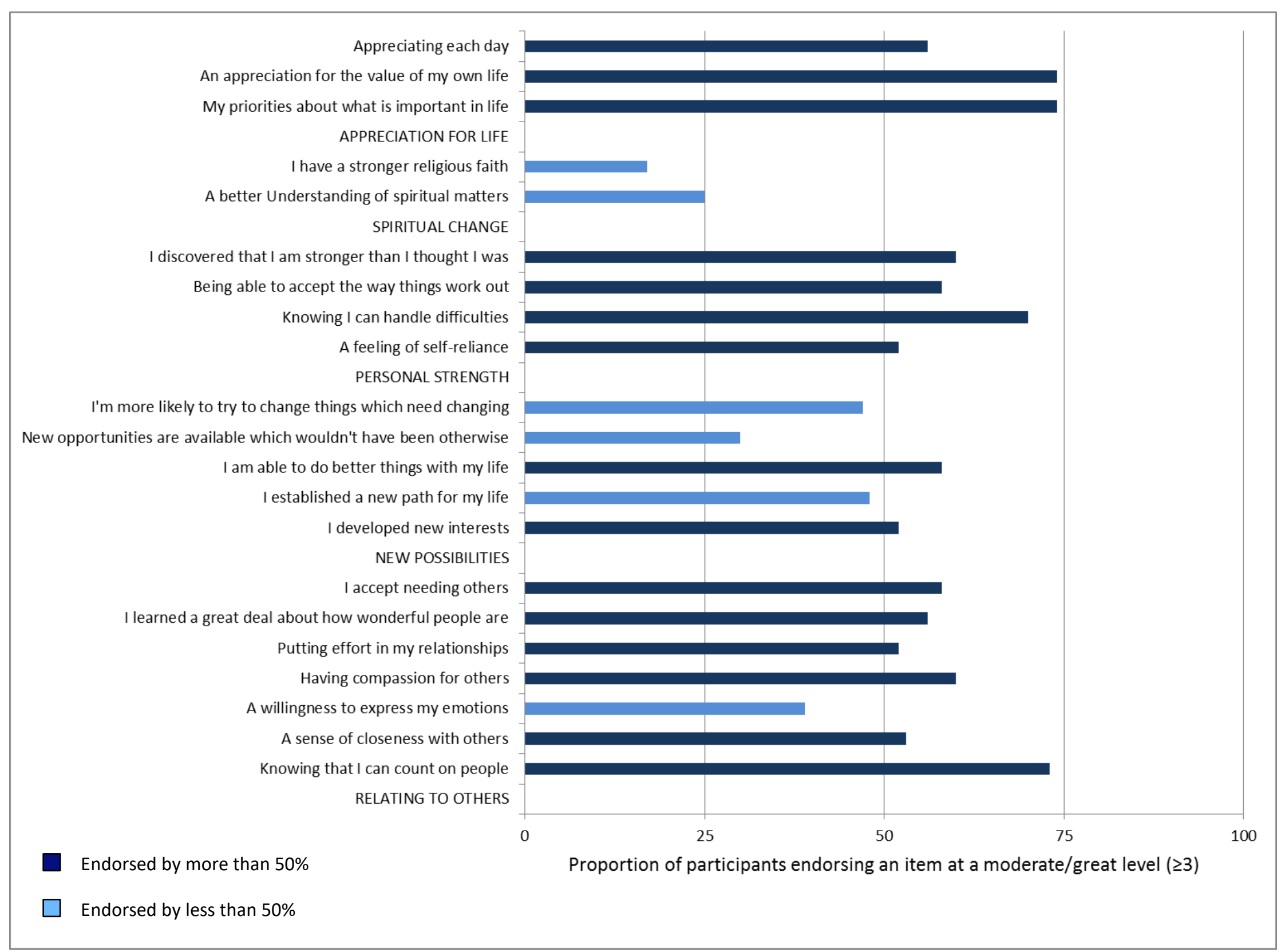

